\title{
Gastric Transposition after Duodenoduodenostomy in Infants with Combined Esophageal and Duodenal Atresia-Report of Three Cases
}

\author{
Zsuzsanna Antal ${ }^{1}$ Tamás Kovács ${ }^{2}$ Péter Vörös ${ }^{1}$ \\ ${ }^{1} 1$ st Department of Pediatrics, Pediatric Surgical Unit, Semmelweis \\ University, Budapest, Hungary \\ 2 Department of Pediatrics, Pediatric Surgical Unit, University of \\ Szeged, Szeged, Hungary
}

Eur J Pediatr Surg 2012;22:470-472.

\author{
Tibor Verebély ${ }^{1}$
}

\section{Introduction}

Esophageal atresia (EA) is a congenital malformation that occurs in $\sim 1$ in 3000 live births. It is commonly present together with other anomalies, the majority involving the VACTERL association (vertebral anomalies, anal atresia, cardiovascular anomalies, tracheoesophageal fistula, renal anomalies, limb defects), while duodenal atresia (DA) is also present in 3 to $6 \%$ of EA patients. ${ }^{1-3}$

A minority of the EA patients, usually without a tracheoesophageal fistula (TEF), need esophageal substitution because of long-gap EA with no possibility of a primary esophagoesophagostomy or following complications with the primary repair. In some cases, the esophageal replacement should be performed in patients who have participated in duodenoduodenostomy in the neonatal period. After colonic interposition and reverse gastric tube esophagoplasty, gastric transposition (GT) is the procedure of choice for esophageal replacement at present in most institutes.

Here, we report three cases of successful GT after duodenoduodenostomy.

\section{Patients and Methods}

GT has been our procedure of choice for esophageal substitution since 1997. In the period between 1997 and 2011, we performed 18 GTs; 17 of the infants had EA, while 1 patient needed esophageal replacement because of a caustic injury. Of the EA patients, three patients had associated DA. Two of them (Cases 1 and 3 ) were basically managed in other institutes and were admitted to the department in Budapest only for the GT.

received

January 7, 2012

accepted

February 14, 2012

published online

May 30, 2012

Address for correspondence and reprint requests Zsuzsanna Antal, M.D., 1st Department of Pediatrics, Semmelweis University, Bókay János utca 53, Budapest 1083, Hungary

(e-mail: antal_zsuzsanna@freemail.hu).

\section{Case 1}

A girl was born after a gestation period of 38 weeks with a birthweight of $2330 \mathrm{~g}$. EA with a proximal TEF and DA were diagnosed postnatally. She underwent duodenoduodenostomy, gastrostomy and cervical esophagostomy with the ligation of the proximal TEF on day 3 of postnatal life. She originated from another country, and no further details are known about her perinatal period. At the age of 8.5 months she was admitted to the department in Budapest for esophageal substitution. GT was performed without complications, and she was discharged on postoperative day 14.

\section{Case 2}

A boy was born after a gestation period of 35 weeks with a birthweight of $2100 \mathrm{~g}$. Prenatal ultrasonography revealed polyhydramnios and an enlarged stomach, which led to the suspicion of DA. The diagnosis was confirmed by the postnatal X-ray with a typical double bubble sign. The esophageal catheter was seen to end at vertebra Th3, demonstrating EA with a distal TEF. Duodenoduodenostomy and primary esophagoesophagostomy were performed in one stage on day 2 of postnatal life. The routine contrast study on postoperative day 7 indicated anastomotic leakage. As this did not respond to conservative treatment, and the physical state of the patient deteriorated dramatically, a second operation was performed on day 12 , involving gastrostomy and cervical esophagostomy. The boy underwent GT at the age of 12 months without any difficulties, and was discharged on postoperative day 17.

\section{Case 3}

A girl was born after a gestation period of 34 weeks, weighting $1980 \mathrm{~g}$. After birth, pure EA was diagnosed

(c) 2012 Georg Thieme Verlag KG Stuttgart · New York
DOI http://dx.doi.org/ 10.1055/s-0032-1313344. ISSN 0939-7248. 
Table 1 Perioperative Details of the Three Patients

\begin{tabular}{|l|l|l|l|l|l|l|l|l|}
\hline & Gender & $\begin{array}{l}\text { Gross } \\
\text { Type }\end{array}$ & $\begin{array}{l}\text { Age at GT } \\
\text { (Months) }\end{array}$ & $\begin{array}{l}\text { Weight at } \\
\text { GT (kg) }\end{array}$ & $\begin{array}{l}\text { Duration of } \\
\text { GT (Minutes) }\end{array}$ & $\begin{array}{l}\text { Start of } \\
\text { Oral Feeding } \\
\text { (Postop. Day) }\end{array}$ & $\begin{array}{l}\text { Discharge } \\
\text { (Postop. Day) }\end{array}$ & $\begin{array}{l}\text { Follow-up } \\
\text { (Months) }\end{array}$ \\
\hline Case 1 & Female & B & 8.5 & 6.8 & 110 & 7 & 14 & 25 \\
\hline Case 2 & Male & C & 12 & 7.0 & 130 & 8 & 17 & 12 \\
\hline Case 3 & Female & B & 11 & 7.6 & 205 & 5 & 11 & 4 \\
\hline
\end{tabular}

GT, gastric transposition; Postop., postoperative.

with a gasless stomach in the X-ray picture. The esophageal catheter ended at the level of vertebra C7. Ultrasonography showed an enlarged stomach and a proximal duodenum full of fluid suspicious of DA. Because of the high termination of the proximal esophageal end and the lack of gas in the stomach, the diagnosis was long-gap EA, a situation in which primary esophagoesophagostomy did not come into consideration. Laparotomy was performed on day 5 of life, and the diagnosis of DA was confirmed. Surgical solution was duodenoduodenostomy and gastrostomy. She underwent a second operation at the age of 1 month because of duodenal anastomotic stricture. The persistantly poor pulmonary condition of the patient suggested an unrecognized proximal TEF, which was confirmed by bronchoscopy at the age of 4 months. After the diagnosis, the TEF was closed from a cervical approach and cervical esophagostomy was performed at the same time. She was admitted to the department in Budapest for GT at the age of 11 months. No difficulties occurred during surgery, and she was discharged on postoperative day 11 .

\section{Results}

Laparotomy revealed only a few adhesions between the bowels and the liver in all three patients during GT, and they could be released with ease even in Cases 2 and 3, where two previous laparotomies had been performed. Retrosternal gastric replacement was performed with pyloromyotomy for the facilitation of gastric emptying in all cases.

-Table 1 demonstrates the perioperative details in three cases.

The duration of the operation, the start of oral feeding, and the patients' release from hospital were comparable to those for the group of patients without DA (-Table 2).
During the follow-up ( 4 to 25 months) all three patients developed normal eating habits and exhibited an appropriate weight gain.

\section{Discussion}

The literature contains several articles on the coexistence of EA and DA. In all cases, the surgical treatment of both pure EA and EA with TEF was primary esophagoesophagostomy. ${ }^{3-8}$ The timing of the DA and EA repairs differed in the various series. In some of them, duodenoduodenostomy was performed in one stage together with esophagoesophagostomy. ${ }^{5,7}$ In other cases, duodenoduodenostomy was performed first with decompressing gastrostomy, and the esophageal repair was performed later. ${ }^{4,6}$ The largest series, published by Ein et al in $2006^{3}$ comprised 24 cases of EA associated with DA or duodenal stenosis in a 30-year period: in 7 patients the repairs were performed in one step, in 11 duodenoduodenostomy was performed first, and in 5 esophagoesophagostomy was the first step. In one case, only gastrostomy was possible. When esophageal repair was performed as the first step, the diagnosis of DA turned out later. Ein et al concluded that staged repair was to be recommended. In our Case 3, the prenatal and postnatal ultrasonographic examinations led to the suspicion of DA, and staged repair was planned.

In the series of Ein et al, 7/24 patients had pure EA, primary esophagoesophagostomy could be performed, and no esophageal substitution was needed. It is interesting that none of those cases had either long-gap EA or complications after the primary esophageal repair.

In our series, two cases were classified as long-gap EA and one manifested anastomotic dehiscence after primary repair. Case 1 was diagnosed and previously managed in another institution, so we cannot be sure about the actual length of

Table 2 Comparison of the Operations and Postoperative Details between EA Patients who Underwent only GT and those who Participated in GT after DA Repair

\begin{tabular}{|l|l|l|l|l|}
\hline & $\boldsymbol{n}$ & $\begin{array}{l}\text { Duration of GT (Min) } \\
\text { (Median [Min-Max]) }\end{array}$ & $\begin{array}{l}\text { Start of Oral Feeding (Postop. Day) } \\
\text { (Median [Min-Max]) }\end{array}$ & $\begin{array}{l}\text { Discharge } \\
\text { (Postop. Day) } \\
\text { (Median [Min-Max]) }\end{array}$ \\
\hline Only GT & 14 & $152.5[115-180]$ & $7.5[4-10]$ & $16.5[9-155]$ \\
\hline GT after DA & 3 & $130[110-205]$ & $7[5-8]$ & $14[11-17]$ \\
\hline
\end{tabular}

EA, esophageal atresia; GT, gastric transposition; DA, duodenal atresia; Min, minimum; Max, maximum; Postop., postoperative. 
the gap between the two esophageal ends. In Case 3, where the proximal stump was situated in the neck and there was no distal TEF, it was quite certain to be a long-gap atresia.

Four of the literature case reports mentioned a dilated, thick-walled distal esophageal stump possibly caused by the associated DA, which facilitated the primary repair of the EA. $^{4-7}$ In our three cases this variation was not observed.

Our literature search did not reveal data concerning esophageal replacement subsequent to duodenoduodenostomy.

\section{Conclusions}

DA is not a contraindication for GT, and GT can be performed safely in patients who participated in duodenoduodenostomy in the neonatal period.

\section{Acknowledgments manuscript. \\ Conflict of Interest}

The authors thank András Pintér, professor emeritus of the Pediatric Surgical Unit, Department of Pediatrics, University of Pécs, Hungary, for help in the completion of the

None

\section{References}

1 van Heurn LWE, Cheng W, de Vries B, et al. Anomalies associated with oesophageal atresia in Asians and Europeans. Pediatr Surg Int 2002;18(4):241-243

2 Holcomb GW III, Rothenberg SS, Bax KMA, et al. Thoracoscopic repair of esophageal atresia and tracheoesophageal fistula: a multi-institutional analysis. Ann Surg 2005;242(3):422-428, discussion 428-430

3 Ein SH, Palder SB, Filler RM. Babies with esophageal and duodenal atresia: a 30-year review of a multifaceted problem. J Pediatr Surg 2006;41(3):530-532

4 Mitani Y, Hasegawa T, Kubota A, et al. Prenatal findings of concomitant duodenal and esophageal atresia without tracheoesophageal fistula (Gross type A). J Clin Ultrasound 2009;37(7): 403-405

5 Pameijer CR, Hubbard AM, Coleman B, Flake AW. Combined pure esophageal atresia, duodenal atresia, biliary atresia, and pancreatic ductal atresia: prenatal diagnostic features and review of the literature. J Pediatr Surg 2000;35(5):745-747

6 Downard CD, Kim HB, Laningham F, Fishman SJ. Esophageal atresia, duodenal atresia, and unilateral lung agenesis: a case report. J Pediatr Surg 2004;39(8):1283-1285

7 Karmarkar SJ, Martucciello G, Repetto P, Karande TP. Primary anastomosis in esophageal atresia type I without a gap. Pediatr Surg Int 1999;15(5-6):376-377

8 Stark Z, Patel N, Clarnette T, Moody A. Triad of tracheoesophageal fistula-esophageal atresia, pulmonary hypoplasia, and duodenal atresia. J Pediatr Surg 2007;42(6):1146-1148 